\title{
GESTÃO AMBIENTAL NAS EMPRESAS DO SETOR DE PETRÓLEO E GÁS EM MOSSORÓ-RN
}

\author{
Rayanne C. Oliveira
}

Núcleo de Estudo de Ciências e Tecnologias Ambientais -NECTA/CEFET-RN

Rayanne-oliveira@hotmail.com

\section{Jailton Barbosa dos Santos}

Professor do Departamento de Indústria e Meio Ambiente do CEFET-RN (UNED-Mossoró) ${ }^{1}$ jailton@cefetrn.br

\section{RESUMO}

Este trabalho constitui uma pesquisa de campo, na qual se estuda a gestão das ações em defesa do meio ambiente realizada nas empresas do setor de petróleo e gás natural e procura identificar a formação e o perfil profissional requeridos para o gestor ambiental nessa área. As atividades produtivas do setor de petróleo e gás geram elevado crescimento econômico para o município de Mossoró (RN). Contudo, grandes impactos ambientais estão aliados a esses processos, como: abertura de estradas, picadas e clareiras; danos à vegetação, solo e fauna; interferência nos recursos hídricos; geração de ruídos, explosões e vazamento de combustíveis e insegurança nas comunidades. Os impactos negativos dessas atividades vêm provocando das empresas, o uso de métodos e técnicas menos agressivos ao meio ambiente, principalmente, no cumprimento da legislação ambiental. O novo cenário evidencia que a proteção ambiental deixa de ser responsabilidade exclusiva dos órgãos oficiais de meio ambiente e passa a ser partilhada por todos os setores da sociedade, inclusive pelas empresas, cujos gestores passam a atuar na vanguarda de políticas públicas, capazes de "pensar global e agir local”, especialmente nessa região onde predominam potenciais riscos e impactos ao meio ambiente oriundos das atividades petrolíferas.

Palavras-Chaves: gestão ambiental, setor produtivo, petróleo, gás natural, impacto ambientais. 


\section{GESTÃO AMBIENTAL NAS EMPRESAS DO SETOR DE PETRÓLEO E GÁS EM MOSSORÓ-RN}

\section{INTRODUÇÃO}

\subsection{A Importância da Consciência Ambiental}

Durante o período da chamada Revolução industrial não havia preocupação com a questão ambiental. Os recursos naturais eram abundantes, e a poluição não era foco da atenção da sociedade industrial e intelectual da época.

A partir da escassez dos recursos naturais, somado ao crescimento desordenado da população mundial e intensidade dos impactos ambientais, surge o paradigma da sustentabilidade dos sistemas econômico e natural, e faz do meio ambiente um tema literalmente estratégico e urgente. $\mathrm{O}$ homem começa a entender a impossibilidade de transformar as regras da natureza e a importância da reformulação de suas práticas ambientais.

\subsection{Os Limites}

A humanidade está usando mais recursos naturais do que o planeta é capaz de repor. Com isso, estamos avançando sobre os estoques naturais da Terra, comprometendo as gerações atuais e futuras segundo o Relatório Planeta Vivo 2002, elaborado pelo WWF.

De acordo com esse relatório, o planeta tem 11,4 bilhões de hectares de terra e espaço marinho produtivos - ou 1,9 hectares de área produtiva per capita. Mas a humanidade está usando o equivalente a 13,7 bilhões de hectares para produzir os grãos, peixes e crustáceos, carne e derivados, água e energia que consome. Cada um dos 6 bilhões de habitantes da Terra, portanto, usa uma área de 2,3 hectares. Essa área é a Pegada Ecológica de cada um. A energia é o fator de maior peso na composição da Pegada Ecológica atual, sobretudo nos países mais desenvolvidos.

A Pegada Ecológica de 2,3 hectares é uma média. Mas há grande diferença entre as nações mais e menos desenvolvidas, como mostra o Relatório Planeta Vivo que calculou a Pegada de 146 países com população acima de um milhão de habitantes. Dados de 1999 mostram que enquanto a Pegada média do consumidor da África e da Ásia não chega 1,4 hectares por pessoa, a do consumidor da Europa Ocidental é de cerca de 5,0 hectares e a dos norteamericanos de 9,6 hectares.

Quando falamos em emissões de poluentes, as diferenças dos índices emitidos pelos países desenvolvidos e em desenvolvimento também são significativas: Um cidadão médio norteamericano, por exemplo, responde pela emissão anual de 20 toneladas anuais de dióxido de carbono; um britânico, por 9,2 toneladas; um chinês, por 2,5; um brasileiro, por 1,8; já um ganês ou um nicaragüense, só por 0,2; e um tanzaniano, por 0,1 tonelada anual. A China e o Leste da Ásia aumentaram em 100\% o consumo de combustíveis fósseis em apenas cinco anos (1990 a 1995). (Wuppertal Institute).

Nos países industrializados cresce cada vez mais o consumo de recursos naturais provindos dos países em desenvolvimento - a ponto de aqueles países já responderem por mais de 80\% do consumo total no mundo. Conforme SACHS (1993), 30\% dos recursos naturais consumidos na Alemanha vêm de outros países; no Japão, 50\%; nos países Baixos, 70\%. 


\subsection{O Desafio}

O grande desafio da humanidade é promover o desenvolvimento sustentável de forma rápida e eficiente. Vivemos então um paradoxo. Sabemos que o tempo está se esgotando, mas não agimos para mudar completamente as coisas antes que seja demasiado tarde. Dizse que uma rã posta na água fervente saltará rapidamente para fora, mas se a água for aquecida gradualmente, ela não se dará conta do aumento da temperatura e tranqüilamente se deixará ferver até morrer. Situação semelhante pode estar ocorrendo conosco em relação à gradual destruição do ambiente natural. Hoje, grande parte da sociedade se posiciona como mero espectador dos fatos, esquecendo-se de que somos todos responsáveis pelo futuro que estamos modelando. Faz-se necessário que passemos a exercer a cidadania planetária, o mais rápido que pudermos.

\subsection{A Luz no Fim no Túnel}

A conscientização ambiental de massa, só será possível com percepção e entendimento do real valor do meio ambiente natural em nossas vidas. O meio ambiente natural é o fundamento invisível das diferenças sócio econômicas entre países desenvolvidos e em desenvolvimento. $\mathrm{O}$ dia em que cada brasileiro entender como esta questão afeta sua vida de forma direta e irreversível, o meio ambiente não precisará mais de defensores. A sociedade já terá entendido que preservar o meio ambiente é preservar a própria espécie, e degradar o meio ambiente, é fragilizar a economia, o emprego, a saúde, e tudo mais. Esta falta de entendimento compromete a adequada utilização de nossa maior vantagem competitiva frente ao mundo: recursos hídricos, matriz energética "limpa" e renovável, biodiversidade, a maior floresta do mundo, e tantas outras vantagens ambientais que nós brasileiros temos e que atrai o olhar do mundo.

Mas, se nada for feito de forma rápida e efetiva, as próximas gerações serão prejudicadas duplamente, pelos impactos ambientais e pela falta de visão de nossa geração em não explorar adequadamente a vantagem competitiva de nossos recursos naturais.

\section{5. Desenvolvimento Sustentável}

As últimas décadas trouxeram à tona diversas preocupações sobre o futuro da humanidade e do planeta Terra, pondo em dúvida muitas verdades à época cristalizadas, dentre elas a que associava desenvolvimento a crescimento econômico ilimitado. Acreditava-se que a imposição de limites ao crescimento seria um entrave às oportunidades que as diversas nações do mundo teriam para se desenvolver. Com base nesse ponto de vista, a sociedade urbano-industrial mais destruiu que criou. A poluição em seus diversos aspectos, a extinção de espécies da flora e da fauna, o desmatamento, o inchamento das cidades, as graves disparidades regionais e a má distribuição de renda são exemplos dos efeitos provocados pelo paradigma do crescimento econômico.

A discussão sobre políticas de desenvolvimento que levassem em conta os impactos sobre o meio ambiente teve início com as discussões do "Clube de Roma" conduzidas por Dennis Meadows e a preocupação em impor Limites ao Crescimento, defendida logo em seguida na Conferência de Estolcomo (1972) e, posteriormente, com Maurice Strong (1973) e a defesa da tese do desenvolvimento preocupado com a dimensão ecológica. A tese de um desenvolvimento preocupado com os recursos naturais chega até a declaração de Cocoyok, que considera não apenas a existência de um mínimo de recursos naturais 
necessários ao bem-estar, mas também à permissão de um máximo. Nessa caminhada, passa-se pelo relatório Dag-Hammarskjold(1975), em que se aponta a interligação entre o abuso de poder e a degradação ecológica. Enfim, chega-se ao Relatório Brundtland, o qual solidificou o conceito de desenvolvimento sustentável, definindo-o como "o desenvolvimento capaz de satisfazer as necessidades do presente sem comprometer a capacidade de as futuras gerações satisfazerem as suas próprias necessidades." (BRUSEKE, 1998)

As teses atuais defendem a adoção de um estilo de desenvolvimento com sustentabilidade para a humanidade, no qual se possa compatibilizar crescimento econômico com um meio ambiente sadio e equilibrado, julgados até então inconciliáveis. Neste pensamento, descarta-se a tese do "crescimento zero", defendida pelo "Clube de Roma”, e apresenta-se uma alternativa ao desastre ambiental planetário que todos temem.

Ignacy SACHS (1993) prefere usar a expressão “ecodesenvolvimento” em lugar de desenvolvimento sustentável e identifica no modelo cinco dimensões de sustentabilidade que, segundo ele, "todo planejamento de desenvolvimento precisa levar em conta": 1) a sustentabilidade social, que se entende como criação de um processo de desenvolvimento que seja sustentado por um outro crescimento e subsidiado por uma outra visão do que seja uma sociedade boa. A meta é construir uma civilização com maior eqüidade na distribuição de renda e de bens, de modo a reduzir o abismo entre os padrões de vida dos ricos e dos pobres; 2) a sustentabilidade econômica, que deve ser tornada possível através da alocação e do gerenciamento mais eficientes dos recursos e de um fluxo constante de investimentos públicos e privados. Nessa dimensão, a eficiência econômica deve ser avaliada em termos macrossociais, e não apenas através do critério da rentabidade empresarial de caráter microeconômico; 3) a sustentabilidade ecológica, que pode ser melhorada se seguidos os seguintes princípios: ampliar a capacidade de carga da Terra, intensificando o uso do potencial de recursos dos diversos ecossistemas, com um mínimo de danos aos sistemas de sustentação da vida; limitar o consumo de combustíveis fósseis e de outros recursos e produtos facilmente esgotáveis ou danosos ao meio ambiente, substituindo-os por outros recursos ou produtos renováveis e/ou abundantes, usando-os de forma não-agressiva ao meio ambiente; reduzir o volume de resíduos e de poluição; intensificar a pesquisa para a obtenção de tecnologias de baixo teor de resíduos e eficientes no uso de recursos para o desenvolvimento urbano, rural e industrial; definir formas de uma adequada proteção ambiental; 4) a sustentabilidade espacial, que deve ser dirigida para a obtenção de uma configuração rural-urbana mais equilibrada e uma melhor distribuição territorial dos assentamentos humanos e das atividades econômicas, 5) a sustentabilidade cultural, incluindo a procura de raízes endógenas de processos de modernização e de sistemas agrícolas integrados, processos que busquem mudanças dentro da continuidade cultural e que traduzam o conceito normativo de ecodesenvolvimento como conjunto de soluções específicas para o local, o ecossistema, a cultura e a área.

Reforçando a visão ecológica de SACHS, surge a proposta de um desenvolvimento mais democrático defendido por autores como Amartya SEN (1999), para quem, o processo de desenvolvimento pode ser considerado como uma ampliação da liberdade humana.

A maioria dos documentos elaborados pela Organização das Nações Unidas (ONU), em especial pelo PNUMA, defende a necessidade de colocarmos na agenda do desenvolvimento local a prática dos gestores prestarem mais atenção à questão da participação das populações que são objeto do desenvolvimento. Entre seus direitos está o de preservar sua identidade cultural e o direito de não ser apartado de sua comunidade. Isso 
indica que não podemos discutir o meio ambiente e o desenvolvimento sem discutirmos o desenvolvimento político. Não é possível erradicar a pobreza simplesmente redistribuindo a riqueza ou a renda; faz-se necessário uma redistribuição melhor do poder.

Ainda na defesa de uma participação da sociedade na discussão do desenvolvimento, ACSELRAD e LEROY(1999) alertam: "É preciso fazer ouvir a voz de outros setores da sociedade e criar condições para que possam desenvolver a sua capacidade de afirmação política (Empowerment), formular efetivamente seus projetos e viabilizá-los”.

A Agenda 21 descreve que "A humanidade de hoje tem a habilidade de desenvolver-se de uma forma sustentável, entretanto é preciso garantir as necessidades do presente sem comprometer as habilidades das futuras gerações em encontrar suas próprias necessidades". O texto destacado pode ser resumido em poucas e simples palavras: desenvolver em harmonia com as limitações ecológicas do planeta, ou seja, sem destruir o ambiente, para que as gerações futuras tenham a chance de existir e viver bem, de acordo com as suas necessidades (melhoria da qualidade de vida e das condições de sobrevivência). Será que é possível conciliar tanto progresso e tecnologia com um ambiente saudável?

Acredita-se que isso tudo seja possível, e é exatamente o que propõem os estudiosos em Desenvolvimento Sustentável, que pode ser definido como: "equilíbrio entre tecnologia e ambiente, relevando-se os diversos grupos sociais de uma nação e também dos diferentes países na busca da equidade e justiça social".

Para alcançarmos o Desenvolvimento Sustentável, a proteção do ambiente tem que ser entendida como parte integrante do processo de desenvolvimento e não pode ser considerada isoladamente; é aqui que entra uma questão sobre a qual talvez você nunca tenha pensado: qual a diferença entre crescimento e desenvolvimento? A diferença é que o crescimento não conduz automaticamente à igualdade nem à justiça sociais, pois não leva em consideração nenhum outro aspecto da qualidade de vida a não ser o acúmulo de riquezas, que se faz nas mãos apenas de alguns indivíduos da população. O desenvolvimento, por sua vez, preocupa-se com a geração de riquezas sim, mas tem o objetivo de distribuí-las, de melhorar a qualidade de vida de toda a população, levando em consideração, portanto, a qualidade ambiental do planeta.

Na tentativa de chegar ao Desenvolvimento Sustentável, sabemos que a Educação Ambiental é parte vital e indispensável, pois é a maneira mais direta e funcional de se atingir pelo menos uma de suas metas, isto é, a participação da população.

\section{FUNDAMENTAÇÃO TEÓRICA}

\subsection{Gestão Ambiental}

De maneira introdutória podemos observar que Gestão Ambiental é uma área de conhecimento nova e possui caráter multidisciplinar. Nota-se também que profissionais dos mais diversos campos vêm atuando na área, nem sempre devidamente habilitados.

Antigamente existia uma divisão nítida entre os defensores da natureza (ecologistas) e os que pregavam a exploração irrestrita dos recursos naturais. Com o advento do termo "desenvolvimento sustentável" tornou-se necessária a formação de pessoas com um 
diferente perfil, profissionais que agregassem a visão ambientalista à exploração "racional" dos recursos naturais, aí surgiram os gestores ambientais.

A Gestão Ambiental visa ordenar as atividades humanas para que essas causem o menor impacto possível sobre o meio ambiente. Esta organização vai desde a escolha das melhores técnicas até o cumprimento da legislação e a alocação correta de recursos humanos e financeiros.

O que deve ficar claro é que "gerir" ou "gerenciar" significa saber manejar as ferramentas existentes da melhor forma possível e não necessariamente desenvolver a técnica ou a pesquisa ambiental em si. Pode estar aí o foco da confusão de conceitos entre a enorme gama de profissionais em meio ambiente. Pois, muitos são parte das ferramentas de Gestão (ciências naturais, pesquisas ambientais, sistemas e outros), mas não desenvolvem esta como um todo, esta função pertence aos gestores ou gerentes ambientais que devem ter uma visão holística apurada.

Existe também uma outra discussão sobre o que é "Gestão Ambiental" e o que é "Gerenciamento Ambiental", alguns defendem que a "gestão" é inerente à assuntos públicos (gestão de cidades, bacias hidrográficas, zonas costeiras, parques) e que gerenciamento refere-se ao meio privado (empresas, indústrias, fazendas e outros). Esta diferença de significados, na verdade, não é importante, o que é realmente importante é promover a Gestão Ambiental em todos os seus aspectos.

Pode-se então concluir que a Gestão Ambiental é conseqüência natural da evolução do pensamento da humanidade em relação à utilização dos recursos naturais de um modo mais sábio, onde se deve retirar apenas o que pode ser reposto ou caso isto não seja possível, deve-se, no mínimo, mitigar a degradação ambiental causada.

Assim, o presente trabalho tem como escopo estudar a gestão das ações em defesa do meio ambiente nas empresas do setor de petróleo e gás natural, procurando identificar a formação dos gestores responsáveis, a demanda do marcado de trabalho e o perfil profissional requerido para o gestor ambiental nessa área. De maneira específica propomos estudar as ações de Gestão Ambiental desenvolvidas nas empresas do setor de Petróleo e Gás; conhecer a formação e o perfil do funcionário responsável pela gestão da política de meio ambiente nas empresas de Petróleo e Gás em Mossoró; identificar a articulação das ações em defesa do meio ambiente do setor produtivo com as ações do poder público; identificar a demanda do mercado de trabalho e o perfil profissional do gestor ambiental para o setor de petróleo e Gás, a fim de subsidiar a implantação do Curso Superior de Graduação Tecnológica em Gestão Ambiental no CEFET-RN.

\subsection{Gestão Ambiental e o Setor de Petróleo na região de Mossoró}

A economia do Rio Grande do Norte, desde a década de 1980, vem passando por diversas mudanças. Observa-se, a partir desse período, um desmonte das atividades econômicas tradicionais como o binômio pecuária-algodão e a exploração da scheelita, ao passo que outras como a fruticultura, a extração de petróleo e gás natural, o turismo e a carcinicultura vão ocupando esse cenário.

O oeste norte-rio-grandense, polarizado pelo município de Mossoró tem hoje grande representatividade econômica em níveis estadual, regional e nacional, uma vez que, nessa região, encontram-se grandes fontes geradoras de emprego e renda: a produção de sal, a 
extração de petróleo, a fruticultura irrigada de exportação, as indústrias ceramista e calcária e, mais recentemente, a produção do gás natural, a carcinicultura e o turismo.

De acordo com as estatísticas oficiais da Prefeitura Municipal, o sal, o petróleo e a agroindústria são os referenciais da economia de Mossoró. A vocação industrial extrativista de Mossoró a conduz hoje ao pódio como principal produtora de sal e de petróleo (em área terrestre do país).

Com relação à produção de petróleo, deve-se ressaltar que a Petrobrás instalou-se na região no ano de 1979. Atualmente, no Campo de Canto do Amaro (BR-110 Mossoró-Areia Branca) são produzidos cerca de 50 mil barris/dia a partir de 3.500 poços perfurados, tornando o município de Mossoró campeão no Rio Grande do Norte em recebimento de royalties de Petróleo. A cidade recebe, em média, R 2 milhões por mês, sendo a maior parte desses recursos investidos na infra-estrutura urbana do município. Além da Petrobrás, várias outras empresas dessa cadeia produtiva têm se instalado no município.

A tabela 1 mostra a relação de Empresas do Setor de Petróleo e Gás com as quais o CEFET-RN/Mossoró possui parceria direta para encaminhamento de alunos estagiários e que serve de campo de pesquisa para o objeto dessa investigação.

Tabela 1- Empresas do setor de petróleo em Mossoró

\begin{tabular}{|l|l|}
\hline Empresa & Endereço \\
\hline AURIZONIA PETRÓLEO & Alto de São Manuel - Mossoró RN \\
\hline AZEVEDO E TRAVASSOS & BR 304 - Mossoró RN \\
\hline BAKER HUGHES DO BRASIL LTDA & Abolição 1 - Mossoró RN \\
\hline BJ SERVICE & Nova Betânia - Mossoró RN \\
\hline BRAIN TECNOLOGIA LTDA & Alto de São Manuel - Mossoró RN \\
\hline CONSTRUTORA ELOS ENGENHARIA & BR 405 - Mossoró RN \\
\hline CRISTENSEN RODER & Alto de São Manuel - Mossoró RN \\
\hline DRILLFOR PERFURAÇÕES DO BRASIL & BR 304 Distrito Industrial - Mossoró \\
\hline EMPERCON & Aeroporto - Mossoró RN \\
\hline ENGEPETROL LTDA & Auto da Conceição - Mossoró RN \\
\hline ENGEQUIP - ENG. DE EQUIPAMENTOS & Governador Dix-Sept Rosado \\
\hline ENTEP & Don Jaime Câmara - Mossoró RN \\
\hline FORTEKS ENG. E SERV. ESPECIAIS LTDA & Planalto 13 de Maio - Mossoró \\
\hline GIUST & BR 405 - Aeroporto - Mossoró RN \\
\hline HALLIBURTON & BR 304 - Mossoró RN \\
\hline HANOVER BRASIL LTDA & Candelária - Natal RN \\
\hline JCI ENGENHRAI LTDA & Shopping Oásis Center - Mossoró RN \\
\hline JIMAG SERVIÇOS LTDA & Centro - Mossoró RN \\
\hline KOCH PETRÓLEO DO BRASIL LTDA & Areia Branca - RN \\
\hline MARINER & Centro - Mossoró RN \\
\hline MARÍTIMA PETRÓLEO E ENG. LTDA & Planalto 13 de Maio - Mossoró RN \\
\hline METAL FORTE B\&S OIL TOLLS & Auto de São Manuel - Mossoró RN \\
\hline
\end{tabular}


OLIVEIRA e SANTOS (2007)

\begin{tabular}{|c|c|}
\hline MI SWACO LTDA & Abolição 1 - Mossoró RN \\
\hline PETRÓLEO BRASILEIRO S.A. & Alto do Sumaré - Mossoró - RN \\
\hline PETROSAL SERVIÇOS INDUSTRIAIS LTDA & Auto da Conceição - Mossoró RN \\
\hline $\begin{array}{lllll}\text { POWER } & \text { WELL BRASIL SERVIÇOS } & \text { DE }\end{array}$ & BR. 304 - Mossoró RN \\
\hline PREST PERFURAÇÕES LTDA & Distrito Industrial - Mossoró RN \\
\hline PREST PRESTAÇÃO DE SERV. GERAIS & Auto do Sumaré - Mossoró RN \\
\hline PROENGE - PROJETOS E ENG. LTDA & Planalto 13 de Maio - Mossoró RN \\
\hline $\begin{array}{llll}\text { RAMIREZ } & \text { SERVIÇOS } & \text { E } & \text { MONTAGENS }\end{array}$ & Centro - Areia Branca RN \\
\hline SANTIAGO ENGENHARIA & Natal - RN \\
\hline SCHLUMGERGER & Planalto 13 de Maio - Mossoró RN \\
\hline SERTEL & BR 304 - Base da Petrobras - Mossoró \\
\hline SETIMAP MANUTENÇÃO E MONTAGEM & Conj. Ving Rosado - Mossoró RN \\
\hline SKANSKA BRASIL LTDA & BR 304 - Don Jaime Câmara - Mossoró \\
\hline SMITH & Abolição - Mossoró RN \\
\hline SOTEP S/A & BR 304-Auto de São Manuel - Mossoró \\
\hline TECNOPETRO & BR 304 - Mossoró RN \\
\hline $\begin{array}{lll}\text { TUCKER } & \text { WIRELINE } & \text { SERVIÇOS } \\
\end{array}$ & Aeroporto - Mossoró RN \\
\hline VIPETRO $\quad-$ & Aeroporto - Mossoró RN \\
\hline
\end{tabular}

Fonte: CIEE-UNED-Mossoró.

\section{METODOLOGIA}

A pesquisa se estrutura em revisão bibliográfica pertinente ao tema; aplicação de questionários e entrevistas com gestores das empresas do setor de Petróleo e Gás; pesquisa de campo com visitas aos empreendimentos do setor; estudo dos regulamentos e diretrizes das empresas do setor de Petróleo e Gás para a área de meio ambiente; estudo dos relatórios de campo dos alunos-estagiários do CEFET-RN nas empresas do setor de Petróleo e Gás.

\section{ANÁLISE DO PERFIL PROFISSIONAL DO GESTOR AMBIENTAL}

O profissional Gestor Ambiental do setor de Petróleo e Gás deve possuir um perfil que o torne apto a atuar no mundo do trabalho, com a finalidade de desenvolver procedimentos da gestão ambiental nesse setor, planejando, executando, avaliando e acompanhando projetos, programas e políticas ambientais a fim de consolidar o desenvolvimento local sustentado.

Essa formação proposta deve propiciar sólidos conhecimentos científicos e tecnológicos, visando ao desenvolvimento de capacidades, habilidades e atitudes que qualifique esses profissionais a fim de que possam: demonstrar uma postura ética que tenha como tripé o desenvolvimento econômico, o social e a prudência ecológica; planejar e executar políticas de educação ambiental com base nas diretrizes do desenvolvimento sustentável; conhecer a importância da biodiversidade, bem como o significado de flora, fauna, preservação e conservação da natureza, princípios ecológicos e ações mitigadoras para o meio ambiente; trabalhar com mapas, zoneamento, GPS, softwares cartográficos e Sistemas de 
Informações Geográficas; gerenciar tecnologias limpas e conceber modelo de inovação tecnológica capaz de minimizar os impactos ambientais decorrentes da atividade produtiva; administrar fontes de energia, visualizando alternativas a fim de possibilitar a ecoeficiência e o uso de energia com sustentabilidade; aplicar normas relativas à saúde, à segurança e ao meio ambiente com vista à melhoria da qualidade de vida no meio ambiente de trabalho; gerenciar políticas de meio ambiente voltadas para o uso racional dos recursos hídricos; aplicar e interpretar normas técnicas e legislação pertinentes às atividades de gestão do meio ambiente, executando práticas e procedimentos jurídicos relacionados ao licenciamento ambiental; administrar áreas reservadas à preservação e/ou conservação dos recursos naturais; desenvolver metodologias de planejamento e gestão do meio ambiente com vista à melhoria da qualidade ambiental e uso sustentável dos recursos naturais; manejar e gerenciar recursos naturais, demonstrando atitudes de iniciativa e visão empreendedora; planejar, administrar e avaliar sistemas de gestão ambiental, planos de resíduos, processos de certificação e projetos ambientais; trabalhar em equipes multidisciplinares no desenvolvimento de projetos, EIA, RIMA, avaliação, auditoria e perícia ambiental; formar e orientar profissionais em função da gestão do meio ambiente e demonstrar atitudes de aquisição contínua de conhecimentos.

Analisando perfis profissionais de gestores qualificados através do PROMINP, na área de Construção e Montagem do setor de Óleo e Gás, concebe-se que para atuar nessa área um Gestor Ambiental tenha o mínimo de conhecimento em: 1- Sistemas Integrados de Gestão (SIG). 2- Meio Ambiente: Sistema Nacional de Meio Ambiente - SISNAMA; competência do CONAMA; Principais Instrumentos da Política Nacional; Constituição Federal e o Meio Ambiente; Princípios Constitucionais; Licenciamento Ambiental; Política Nacional do Meio Ambiente; Lei Federal N 9.605/1998; Hierarquia das Leis; Conceitos Básicos em Meio Ambiente. 3- Sistema de Gestão Ambiental - SGA: Princípios e Elementos Básicos do SGA; Avaliação Ambiental Inicial; Política Ambiental; Planejamento do Processo Tarefas e Atribuições da Gestão Ambiental Empresarial; Implementação e Operação do SGA Medição e Avaliação; Roteiro para implantação do SGA; Requisitos da Norma NBR ISO 14001:2004; Documentação do SGA; Sistemas de Gestão de resíduos Sólidos. 4 - Gestão da Segurança e Saúde Ocupacional (SSO): Documentos Legais - Normas Regulamentadoras; Considerações Gerais -Aspectos da NR 1; Programa de Prevenção de Riscos Ambientais - NR 9; Classificação dos Agentes de Perigos nos Ambientes de Trabalho; Conceitos de Avaliação de Risco. A Norma OHSAS 18001:1999; O Conteúdo da Norma; Objetivos da Norma; Termos e definições; Elementos do Sistema de Gestão da SSO e 5- Conhecimento das Etapas do Controle de Processo no Sistema de Gestão da Qualidade.

\section{CONCLUSÃO}

A dinâmica econômica do setor petrolífero, aliada à atração de empresas dessa cadeia produtiva, vem aumentando significativamente a necessidade de qualificação de mão-deobra em todo o setor. Embora as atividades produtivas do setor de petróleo gerem altos rendimentos e desenvolvimento econômico para o município e região, grandes impactos ambientais estão aliados às atividades da indústria do petróleo e gás natural, como: abertura de estradas, picadas e clareiras; danos à vegetação, solo e fauna a partir da construção de instalações auxiliares; interferência nos recursos hídricos subterrâneos causados pelos estudos hidrogeológicos; levantamentos geofísicos com possibilidade de gerar ruídos, explosões e vazamento de combustíveis; perfuração de poços para pesquisa e 
preparação da lavra, com a possibilidade de prejuízo à flora, às águas subterrâneas, ao solo e à segurança de comunidades.

O alto nível de impactos negativos da atividade petrolífera vem provocando a preferência de uso por métodos e técnicas considerados menos agressivos ao meio ambiente, além das exigências impostas pela legislação ambiental vigente, fatores que impõem grandes desafios ao setor produtivo. O novo cenário evidencia que a proteção ambiental deixa de ser considerada responsabilidade exclusiva dos órgãos oficiais de meio ambiente e passa a ser compartilhada por todos os demais setores da sociedade, inclusive pelas empresas.

Assim sendo, concebe-se a Gestão Ambiental como função capaz de contribuir para a construção de uma sociedade cujo desenvolvimento esteja aliado à sustentabilidade, destacando-se a necessidade desse gestor responsável possuir qualificação específica para gerenciar os processos produtivos, cuja postura de atuação se oriente numa perspectiva preventiva e/ou mitigadora.

Nesse sentido, torna-se por demais importante que esse profissional tenha um perfil delineado por um conjunto de competências que o torne capaz para atuar frente ao mundo produtivo e na vanguarda de políticas públicas, capazes de "pensar global e agir local", especialmente numa região onde predominam atividades produtivas, potenciais de riscos e impactos ao meio ambiente, como é o caso daquelas do setor de petróleo e gás natural.

\section{REFERÊNCIAS BIBLIOGRÁFICAS}

ACSELRAD, Henri \& LEROY, Jean -Pierre. Novas Premissas de Sustentabilidade Democrática. Cadernos de Debates - Brasil Sustentável e Democrático, n²1, Rio de Janeiro: Fase, 1999, p.11-47.

BRASIL. AGENCIA NACIONAL DE PETRÓLEO - ANP. www.anp.gov.br

CAVALCANTI, Clovis (org.). Meio ambiente: Desenvolvimento sustentável e políticas públicas. São Paulo: Cortez. 2003.

COUTO, D. S. e SANTOS, J. B. . A chama do desenvolvimento ilumina Mossoró: profissionalização e geração de emprego no setor do gás natural, artigo, Jornal $O$ Mossoroense,11/08/2005.

Profissionalização e geração de emprego e renda no setor do gás natural em Mossoró. III Congresso de Iniciação Científica. Natal (RN): CEFET-RN, 22 a 23 de dezembro de 2005.

Estudo da demanda de formação profissional e geração de emprego e renda no setor de gás natural em Mossoró-RN. Projeto de pesquisa. Mossoró-RN: CEFET-RN/ Diretoria de Pesquisa / NECTA /Unidade de Mossoró, abril a dez./2005. DONAIRE, Denis. Gestão ambiental na empresa. São Paulo: Atlas,1995.

FERNANDES FILHO, A. M. et al.. Avaliação de impacto ambiental. João Pessoa: SUDEMA,1993

FIORILLO, Celso Antônio Pacheco. Curso de Direito Ambiental Brasileiro. - 6 a edição ampl. - São Paulo: Saraiva, 2005. 
IBAMA. Instituto Brasilito de Meio Ambiente e Recursos Naturais Renováveis < www.ibama.gov.br>

IDEMA(RN). Instituto de Desenvolvimento e Meio Ambiente do RN $<$ www.idema.rn.gov.br $>$

MEDEIROS, T.C.L. e SANTOS, J.B. Formação profissional para o setor de petróleo: chave para a sustentabilidade em Mossoró(RN). CEFET-RN, Natal: I CONNEPI. 5 a 8 de dezembro de 2006.

MOURA, Luiz Antônio Abdalla. Qualidade e gestão ambiental: sugestão para implantação das normas ISO-14.000 nas empresas. São Paulo:Oliveira Mendes,1998.

OLIVEIRA, Robério Fernandes Alves de. Sistemas Integrados de Gestão. CEFET de Química do Rio de Janeiro. Rio de Janeiro (RJ): PETROBRAS-PROMINP, 2006.

PROJETO do Curso Superior de Tecnologia em Gestão Ambiental na modalidade à

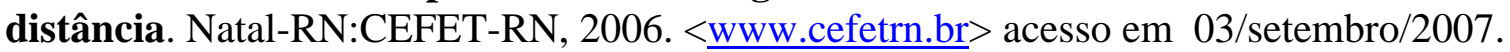

SACHS, Ignacy. Estratégias de transição para o século XXI: Desenvolvimento e Meio Ambiente. São Paulo: Studio Nobel Fundap, 1993.(O desafio da ECO 92: desenvolvimento com justiça em um planeta habitável. p. 11-55)

SANTOS, J. B. ; SOUZA, A. C. Cenários de Desenvolvimento Sustentável em Mossoró-RN: Uma análise Prospectiva sobre Políticas de Geração de Trabalho e Renda. Painel, Anais do VI Seminário Integrador da Rede PRODEMA, Barra dos Coqueiros-SE:19 a 22 de agosto de 2001.

SANTOS, J. B. . Planejando o Desenvolvimento Regional Sustentável: a fantasia organizada do Projeto Áridas, Jornal de Fato, 15/09/2001.

. O uso do gás natural em Mossoró-RN e as Políticas públicas para o setor. Fortaleza-CE: Congresso Internacional sobre Desenvolvimento e meio Ambiente: Política, desenvolvimento e Sustentabilidade,13 de setembro de 2002.

. O poder Público como Indutor do Desenvolvimento Sustentável: o Gás Natural em Mossoró-RN. Dissertação de Mestrado. Mossoró: UERN, 2003.

As Relações entre Desenvolvimento Sustentável, Poder Público, Educação e Trabalho: O Gás Natural em Mossoró-RN, Painel e trabalho Completo. São Luiz-MA, Anais do V Congresso Internacional de Educação, julho/2004.

A Responsabilidade Social do Poder Público na Indução do Desenvolvimento Sustentável: O Gás Natural em Mossoró-RN. Revista HOLOS (CEFET-RN). Natal, ano 20, outubro/2004. ISSN 1807-1600.

A Responsabilidade Social do Poder Público na Educação Profissional: Demanda de Qualificação do Trabalhador em Mossoró-RN. In: VI Simpósio UERN de Pesquisa e Extensão. XI Encontro de Pesquisa e Extensão - ENCOPE. Mossoró : UERN, 2005. v. 1. 
. Educação Profissional em Mossoró: a experiência do CEFET-RN na formação de Trabalhadores para o setor de petróleo e gás natural, Cadernos Temáticos - Vol. 1- caderno:Comunidade esse é meu lugar - Brasília: SETEC/MEC, março/2005.

Impactos sócio-econômicos e ambientais de uma nova atividade econômica em expansão: o gás natural em Mossoró-RN, Painel, Anais. FortalezaCE(UECE): 57 ${ }^{\text {a }}$ SBPC, 18/07/2005.

SARNO, Ruy. Gestão Ambiental em Projetos de Energia. Portal GasEnergia, acessado em 08 de setembro de 2002.

SEIFFERT, Mari Elizabete Bernardini. ISO 14001 Sistemas de Gestão Ambiental: implantação objetiva e econômica. São Paulo: Atlas, 2005.

SEN, Amartya. El Futuro de Estado de Bienestar. Conferência pronunciada em "Círculo de Economia” - Barcelona, Espanha. Texto publicado em La Factoria n8. fev/1999.

SILVA, José Afonso. Direito ambiental constitucional. São Paulo: Malheiros, 2003.

TOCCHETTO. Marta Regina Lopes. Qualidade Ambiental e Ecoeficiência: nova postura para indústrias de alto impacto. - Universidade Federal de Santa Maria PEREIRA, Lauro Charles - Embrapa Meio Ambiente-SP. http://jus2.uol.com.br/doutrina/texto.asp?id=1202>. Acesso em: 03 abr. 2006. 